Communication

\title{
A Coumarin-Benzothiazole Derivative as a FRET-Based Chemosensor of Adenosine $5^{\prime}$-Triphosphate
}

\author{
Moustafa T. Gabr ${ }^{1, *(1)}$, Mostafa M. H. Ibrahim ${ }^{2,3}$, Anuj Tripathi ${ }^{4}$ and Chetti Prabhakar ${ }^{4}(\mathbb{D}$ \\ 1 Department of Medicinal Chemistry, Faculty of Pharmacy, Mansoura University, Mansoura 35516, Egypt \\ 2 Department of Pharmacognosy, Faculty of Pharmacy, Mansoura University, Mansoura 35516, Egypt \\ 3 Department of Basic Pharmaceutical and Toxicological Sciences, College of Pharmacy, University of \\ Louisiana at Monroe, Monroe, LA 71201, USA \\ 4 Department of Chemistry, National Institute of Technology, Kurukshetra 769008, India \\ * Correspondence: gabr@stanford.edu; Tel.: +1-319-359-9500
}

Received: 7 June 2019; Accepted: 22 July 2019; Published: 25 July 2019

\begin{abstract}
A coumarin-benzothiazole ratiometric probe of ATP was designed and synthesized. The probe is based on incorporation of benzothiazole scaffold as a donor and coumarin nucleus as an acceptor in a single Förster resonance energy transfer/fluorescence resonance energy transfer (FRET) sensing platform. The sensor can detect ATP in aqueous solution with high selectivity over other nucleotide polyphosphate (NPP) anions. Binding of ATP to the sensor results in modulation of FRET efficiency between the donor and the acceptor which afforded a linear relationship between FRET signal and ATP $(0.1-10 \mu \mathrm{M})$. A limit of detection (LOD) of $94.5 \mathrm{nM}$ was quantified for FRET sensing of ATP by the probe. In addition, Job plot analysis revealed 1:1 binding interaction between the probe and ATP. The FRET probe was successfully utilized in monitoring ATP hydrolysis by apyrase in aqueous solution.
\end{abstract}

Keywords: coumarin; FRET; ATP; sensor

\section{Introduction}

Förster resonance energy transfer (FRET) or fluorescence resonance energy transfer (FRET) is a mechanism by which energy can be transferred from an electronic excited light sensitive donor chromophore to another light sensitive acceptor chromophore [1]. FRET is a non-invasive approach with nanometer resolution distinctive in generating sensitive fluorescence signals to determine if two fluorophores are within a certain distance of each other in the 1-10 $\mathrm{nm}$ range with a wide array of applications in biology and chemistry [2]. The most significant FRET measurement approaches are fluorescence intensity based approach, fluorescence lifetime based approach, and fluorescence anisotropy based approach [3]. Ratiometric imaging depends on recording fluorescence intensities at two wavelengths simultaneously and calculating the ratio between the two intensities. This technique significantly reduces the effects of environmental changes around the sensor and consequently results in enhanced sensitivity [3-7].

ATP is the prevalent energy unit in all living organisms. Current ATP quantification methods rely on luciferase-based bioluminescent assays. Cellular extraction of ATP is required in these assays which results in large variations in the cellular ATP concentration [8,9]. FRET-based ATP biosensors can be optimized to accurately image and measure ATP concentrations without cellular damage. A genetically encoded FRET-based ATP biosensor was optimized for enhanced ATP affinity at low temperatures. The new biosensor was further utilized in visualization of ATP dynamics at single-cell resolution in Drosophila melanogaster and Caenorhabditis elegans [10]. The ratiometric ATP 
sensor was also re-engineered to be expressed on cell surfaces which enabled real time imaging and reliable quantitation of extracellular ATP [11]. Moreover, ATP and ADP-selective fluorescent sensors were designed from ATP and ADP-selective RNA aptamer and converting the RNA aptamer to a fluorescent ribonucleopeptide (RNP) complex which were converted to covalently-linked RNP sensors for application in the simultaneous detection of ATP and ADP in solution. This approach enabled facile and quantitative detection of both ATP and ADP using the dual specific sensors simultaneously in a chemical reaction [12].

Several molecular probes for fluorescent sensing of ATP have been reported [13-18]. However, these probes function through monitoring changes in single emission intensities which is vulnerable to alterations from external factors such as temperature, $\mathrm{pH}$, and solvent polarity. On the other hand, ratiometric sensing probes represent a precise sensing platform based on detecting signals at different wavelengths and determining their intensity ration [19]. Limited examples of ratiometric sensors of ATP have been reported [20-23]. Significant drawbacks of previously reported ATP ratiometric probes such as non-selective response to ATP [22] and synthetic challenges [23] limit their potential applications in ATP sensing. Therefore, it is of great importance to develop a ratiometric probe of ATP that is synthetically accessible and possesses a selective response to ATP.

Coumarins are classic push-pull fluorescent dyes that have been reported in numerous FRET sensing platforms [24-26]. For example, a coumarin-rhodamine fluorescent probe (1 in Figure 1) was reported for ratiometric sensing of $\mathrm{Hg}^{2+}$ in living cells [25]. Recently, coumarin/benzothiazole probe ( 2 in Figure 1 ) has been reported as a sensitive fluorescent sensor for the detection of $\mathrm{Pd}^{2+}$ in aqueous solutions. [27]. Benzothiazole-based chemosensors have been developed for sensitive detection of biologically relevant as well as toxic metal ions [28,29]. For example, the benzothiazole sensor 3 (Figure 1) enabled ratiometric fluorescent sensing of zinc ion in living cells. Remarkably, the fluorescence response of 3 to $\mathrm{Zn}{ }^{\mathrm{II}}$ was further utilized in pyrophosphate (PPi) sensing in physiological conditions [28]. Herein, we report a coumarin-benzothiazole probe as a ratiometric sensor of ATP in aqueous conditions.<smiles>CCN(CC)c1ccc2c(c1)Oc1cc(N(CC)CC)ccc1C21c2ccccc2C(=O)N1NC(=S)Nc1cccc(NC(=O)c2cc3ccc(N(CC)CC)cc3oc2=O)c1</smiles><smiles>Cc1cc(/C=N/C(CO)(CO)CO)c(O)c(-c2nc3ccccc3s2)c1</smiles>

Figure 1. Chemical structures of coumarin-based and benzothiazole-based fluorescent probes. 


\section{Materials and Methods}

\subsection{General}

All reagents and solvents were purchased from commercial sources and used as supplied. Compound 4 was obtained from Aurora Fine Chemicals. Chemical reactions were monitored by thin-layer chromatography (TLC). Column chromatography was performed using silica gel (200-300 mesh). UV-vis absorption spectra were recorded on a Perkin Elmer Lambda-25 spectrometer. Fluorescence spectra were recorded on a Hitachi F-4500 fluorescence spectrometer. The fluorescence decays were collected from picosecond time domain spectrometer that employed Time Correlated Single Photon Counting (TCSPC) technique (Model Fluorocube, IBH Jobin Yvon 6.1). ${ }^{1} \mathrm{H}$ NMR and ${ }^{13} \mathrm{C}$ NMR spectra were recorded on a Bruker Avance II $400 \mathrm{MHz}$ spectrometer. High Resolution Mass Spectra were recorded on ESI-Q-TOF mass spectrometer.

\subsection{Synthesis}

Compound $4(3.28 \mathrm{~g}, 9.00 \mathrm{mmol})$ was dissolved in $300 \mathrm{~mL}$ of dichloromethane. The flask was charged with methyl iodide $(0.70 \mathrm{~mL}, 9.00 \mathrm{mmol})$. The reaction was allowed to stir at room temperature for $6 \mathrm{hr}$. The reaction mixture was diluted with water and extracted with dichloromethane $(2 \times 150 \mathrm{~mL})$ and the combined organic fractions were dried over anhydrous $\mathrm{Na}_{2} \mathrm{SO}_{4}$, filtered, and concentrated under reduced pressure. The crude product was purified by flash column chromatography using $5 \%$ methanol in dichloromethane to yield 5 as dark yellow solid. Yield $56 \%$. Mp $209-211{ }^{\circ} \mathrm{C} .{ }^{1} \mathrm{H}$ NMR $\left(400 \mathrm{MHz}, \mathrm{CDCl}_{3}\right) \delta 1.58(\mathrm{~d}, 3 \mathrm{H}, J=3.4 \mathrm{~Hz}), 2.15(\mathrm{~s}, 3 \mathrm{H}), 3.67(\mathrm{~s}, 6 \mathrm{H}), 4.21(\mathrm{~s}, 2 \mathrm{H}), 5.78(\mathrm{~m}, 1 \mathrm{H}), 6.15(\mathrm{~s}$, 1H), 7.14-7.18 (m, 2H), 7.68-7.73 (m, 4H), $8.29(\mathrm{~d}, 1 \mathrm{H}, J=7.5 \mathrm{~Hz}) .{ }^{13} \mathrm{C}$ NMR $(100 \mathrm{MHz}$, DMSO-d 6 ) $\delta$ 23.4, 24.3, 57.1, 68.3, 81.3, 96.5, 115.6, 117.0, 120.7, 123.2, 125.5, 130.1, 130.3, 132.4, 136.6, 140.5, 145.2, 151.0, 157.0, 163.5, 167.9. HRMS (ESI): Calcd for $\mathrm{C}_{22} \mathrm{H}_{23} \mathrm{~N}_{2} \mathrm{O}_{2} \mathrm{~S}$ [M] ${ }^{+}$, 379.1480; found, 379.1477.

\subsection{Job Plot Analysis}

A Job plot was constructed to determine the binding stoichiometry between 5 and ATP by monitoring the change in $F_{325} / F_{469}$ ratio as a function of 5/ATP mole fraction. Stock solutions (20 $\mu \mathrm{M}$ each) of 5 and ATP were prepared. Samples were prepared with different mole fractions of 5 and ATP while maintaining the total concentration of ([5] + [ATP]) for each sample at $10 \mu \mathrm{M}$.

\subsection{Computational Studies}

All the density functional theory calculations (DFT) were performed using Gaussian 16 quantum chemical program. Initially, individual molecules (probe molecule in its cationic state and ATP with four negative charges) were optimized at M06-2X, a hybrid meta-GGA based Minnesota exchange-correlation functional (54\% Hartree-Fock exchange) was used in combination with 6-31 G (d) basis set. During the optimization process, no symmetry constraints were imposed and to ensure that there were no imaginary frequencies on the potential energy surface the optimized geometries were subjected to vibrational frequency analysis calculations and were without any imaginary frequencies. Subsequently, the individual geometries obtained at M06-2X level were used for the generation of initial structure of the complex and was optimized at same functional and basis set.

\section{Results and Discussion}

\subsection{Synthesis}

As shown in Scheme 1, the probe 5 was simply prepared through a one-step reaction that included quaternization of the tertiary amine 4 in dichloromethane using methyl iodide at room temperature. 


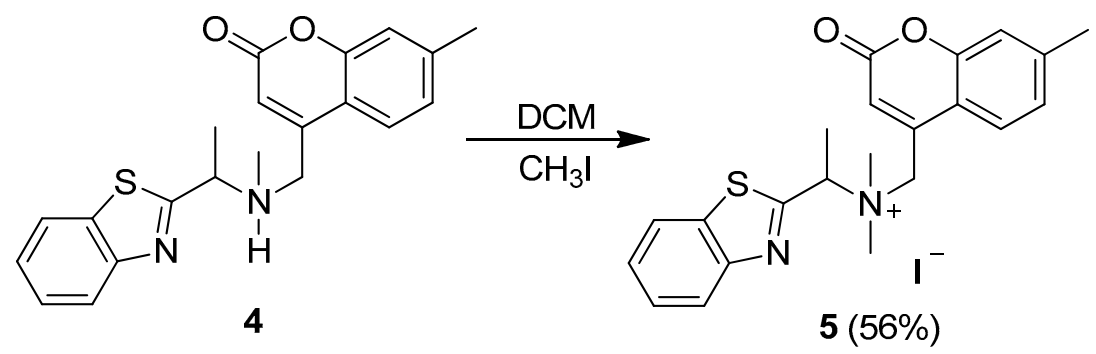

Scheme 1. Synthesis of probe 5 .

\subsection{Design of Probe 5}

The design strategy of probe 5 as a FRET sensor was based on linking 2-methyl benzothiazole nucleus (6 in Figure 2) as a donor to 4,7-dimethyl coumarin (7 in Figure 2) as an acceptor via a flexible short aliphatic linkage. An overlap of the emission spectrum of the donor and the absorption spectrum of the acceptor is essential for an efficient FRET sensor. As shown in Figure 3A, the absorption spectrum of 7 largely overlapped with the emission spectrum of 6 . In addition, the emission wavelengths of 6 and 7 were well resolved with a $144 \mathrm{~nm}$ Stokes shift (Figure 3A and Figure S1). Moreover, the donor 6 displayed maximum absorbance wavelength at $\sim 300 \mathrm{~nm}$ (Figure S2). As shown in Figure 3A, the acceptor coumarin had negligible absorption at $300 \mathrm{~nm}$ which allowed selective excitation of the donor 6 in the proposed FRET probe 5. The emission spectrum of probe 5 in HEPES buffer (pH 7.4) upon excitation at maximum absorbance wavelength of the donor $(300 \mathrm{~nm})$ revealed an emission centered at $469 \mathrm{~nm}$ which was attributed to the acceptor (Figure 3B). The quantum yield of the emission of the probe 5 at $469 \mathrm{~nm}$ was determined to be $12.5 \%$ relative to quinine sulfate in $0.1 \mathrm{M} \mathrm{H}_{2} \mathrm{SO}_{4}$. A minimal emission signal of the donor at $325 \mathrm{~nm}$ was observed (Figure 3B). Therefore, the emission profile of 5 revealed efficient FRET from donor to the acceptor in aqueous solution. The lifetime of the emission of 6 was 9.49 ns, however, the lifetime of the emission of benzothiazole nucleus in 5 was shortened to 3.13 ns, which is a further indicative of efficient FRET in probe 5 under our experimental conditions.

We envisioned that positively charged aliphatic linker between the donor and the acceptor in 5 would enable modulation of FRET efficiency upon interaction with biologically relevant polyanionic species through electrostatic interactions. It is proposed that complexation of the quaternized ammonium cation in 5 with polyanionic species will affect the flexibility of the aliphatic linker between the donor and the acceptor resulting in modulation of FRET efficiency. Moreover, the electrostatic interactions between positively charged 5 and polyanionic species would result in aggregation of 5 and consequently attenuated emission owing to aggregation-caused quenching (ACQ).

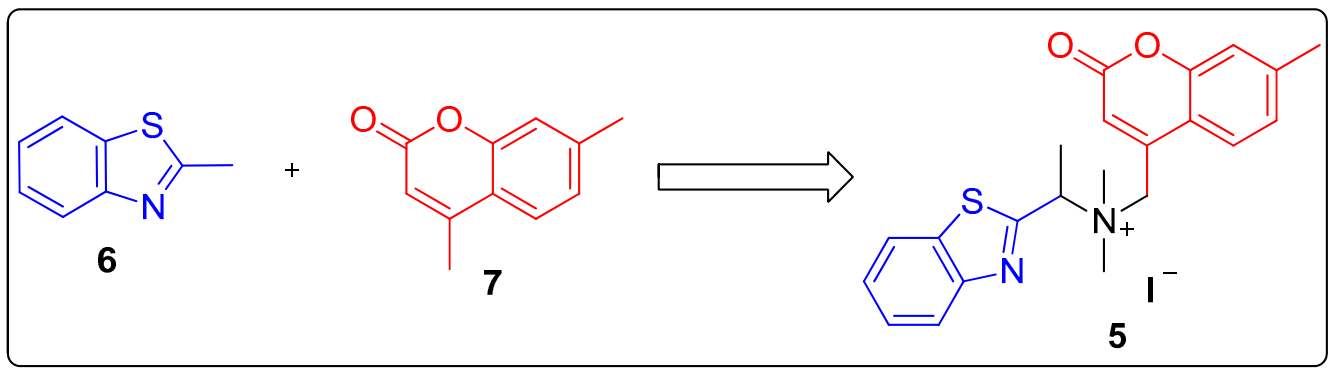

Figure 2. Design strategy of probe 5. 

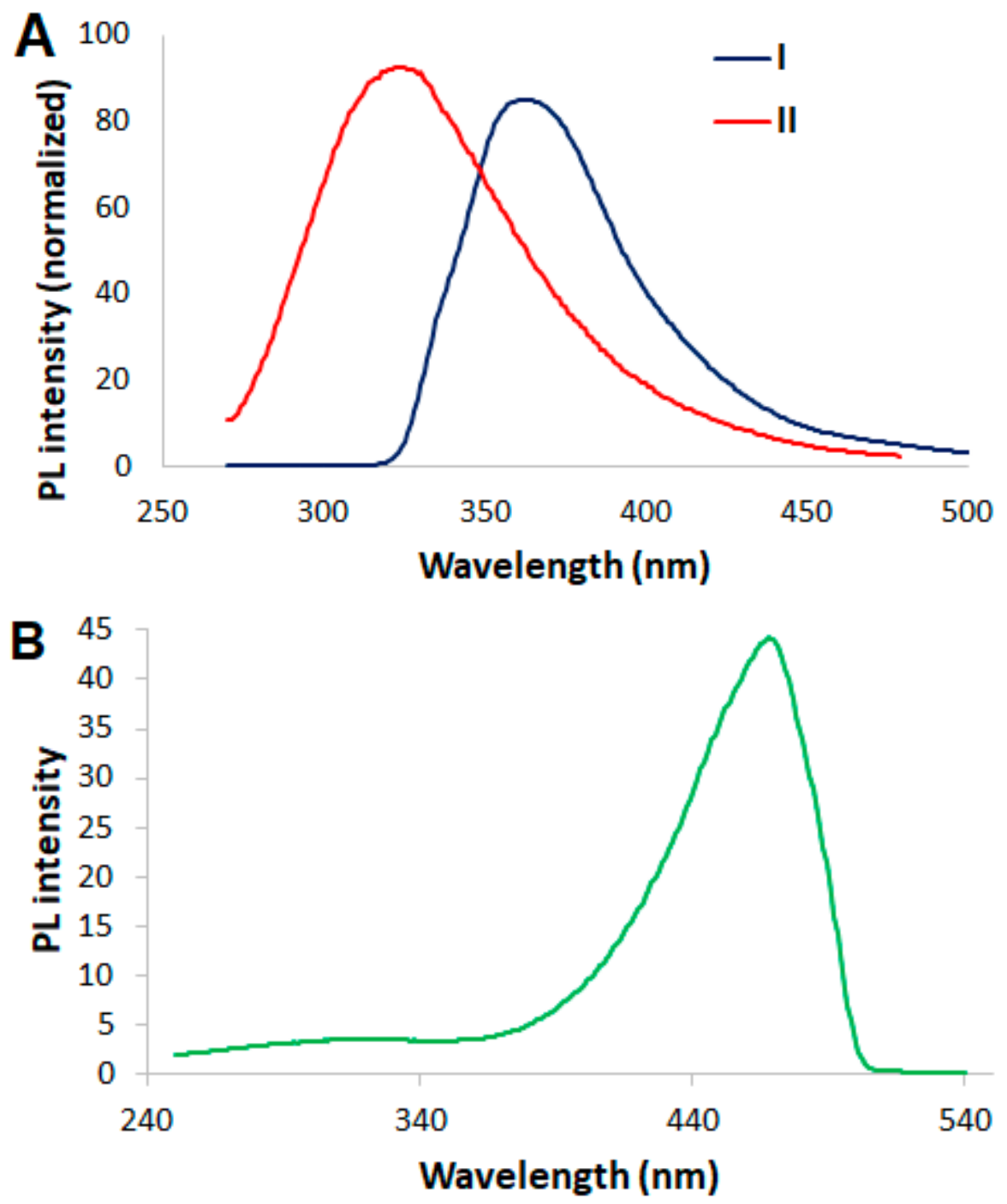

Figure 3. (A) The absorbance spectrum of $7(10 \mu \mathrm{M})(\mathrm{I})$ and the emission spectrum of $6(10 \mu \mathrm{M})$ (II).

(B) The emission spectrum of the probe $5(10 \mu \mathrm{M})$ in HEPES buffer $(\mathrm{pH} 7.5)$.

\subsection{FRET Sensing of ATP by Probe 5}

In order to validate our design strategy, the association of probe 5 with ATP was studied via monitoring changes in its emission profile. Addition of various concentrations of ATP $(0-50 \mu \mathrm{M})$ to an aqueous solution of $5(10 \mu \mathrm{M})$ in HEPES buffer ( $\mathrm{pH} 7.5)$ resulted in significant attenuation of the emission signal of the acceptor at $469 \mathrm{~nm}$ which was attributed to ACQ effect. Consequently, the emission signal of the benzothiazole donor in 5 at $325 \mathrm{~nm}$ gradually increased revealing a reduced FRET efficiency from the donor to the acceptor. As shown in Figure $4 \mathrm{~A}$, the ratio $(R)$ of the emission intensities of 5 at 469 and $325 \mathrm{~nm}\left(R=F_{469} / F_{325}\right)$ decreased from 6.68 to $0.49(R=6.19)$ upon variation of ATP concentration $0-50 \mu \mathrm{M}$. The variation in the $F_{469} / F_{325}$ of 5 was examined in the presence of other nucleotide phosphate anions such as ADP and AMP. A remarkable differentiation between $F_{469} / F_{325}$ of 5 in the presence of ATP in comparison to ADP and AMP is evident from Figure 4A. As shown in Figure $4 \mathrm{~B}$, a linear relationship between the emission response of the probe 5 and ATP $(0.1-10 \mu \mathrm{M})$ was further demonstrated. The limit of detection (LOD) of 5 for ATP was quantified to be $94.5 \mathrm{nM}$. LOD is defined as the concentration of analyte that corresponds to three times the signal-to-noise ratio $(\mathrm{S} / \mathrm{N}=3)$ [30]. The selective and sensitive response of 5 to ATP represents an interesting platform for further utilization in biological assays. 

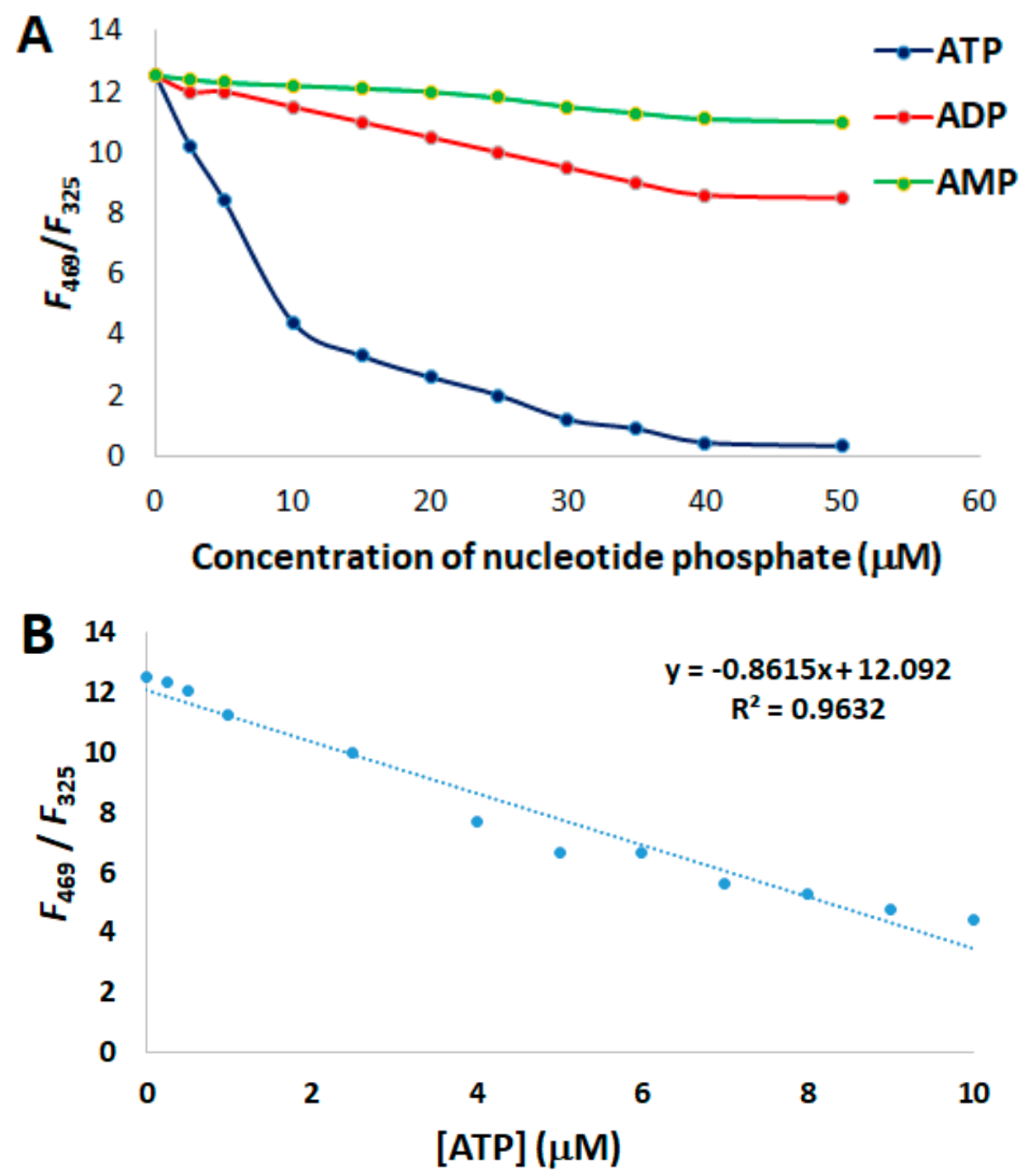

Figure 4. (A) Dependence of emission ratio of the probe $5\left(R=F_{469} / F_{325}\right)$ on the nucleotide concentration. (B) Linear relationship between emission response of the probe and ATP concentration. [5] $=10 \mu \mathrm{M}$; excitation wavelength $=300 \mathrm{~nm}$.

\subsection{Aggregation of 5}

The proposed ATP sensing mechanism of 5 is based on aggregation of 5 upon electrostatic interactions with negatively charged ATP. Thus, the aggregation of 5 under our experimental conditions was further studied using dynamic light scattering (DLS). The probe 5 solution in HEPES buffer ( $\mathrm{pH}$ 7.5) in the absence of ATP revealed the presence of small nanoaggregates with average size of $6.4 \pm 0.9 \mathrm{~nm}$ (Figure S3). However, upon addition of ATP (1 equivalent) to the aqueous solution of 5, larger nanoaggregates with an average size of $435 \pm 5.7 \mathrm{~nm}$ were detected (Figure S4). These results are in consistent with our proposed ATP sensing mechanism of 5.

\subsection{Analysis of Selectivity and Stoichiometry of Binding}

In order to examine the fluorescence response of sensor 5 in the presence of other anions, the emission ratio of the probe $F_{325} / F_{469}$ was detected in the presence of the equimolar concentrations of the following anions: $\mathrm{AcO}^{-}, \mathrm{F}^{-}, \mathrm{Br}^{-}, \mathrm{I}^{-}, \mathrm{Cl}^{-}, \mathrm{PO}_{4}{ }^{3-}, \mathrm{SO}_{4}{ }^{2-}, \mathrm{CO}_{3}{ }^{2-}, \mathrm{HCO}_{3}{ }^{-}, \mathrm{NO}_{3}{ }^{-}$, and $\mathrm{N}_{3}{ }^{-}$. As shown in Figure 5A, remarkable sensitivity of probe 5 for ATP over a variety of 11 anions is evident. Aiming to gain further insight on the binding interaction between probe 5 and ATP, the binding stoichiometry between ATP and 5 was examined through construction of a Job Plot. The $F_{325} / F_{469}$ ratio of 5 as 
function of mole fraction of ATP was monitored (Figure $5 \mathrm{~B}$ ). The maximum $F_{325} / F_{469}$ ratio was detected at $\sim 0.5$ mole fraction of ATP, which is an indicative of a 1:1 (5:ATP) binding stoichiometry.

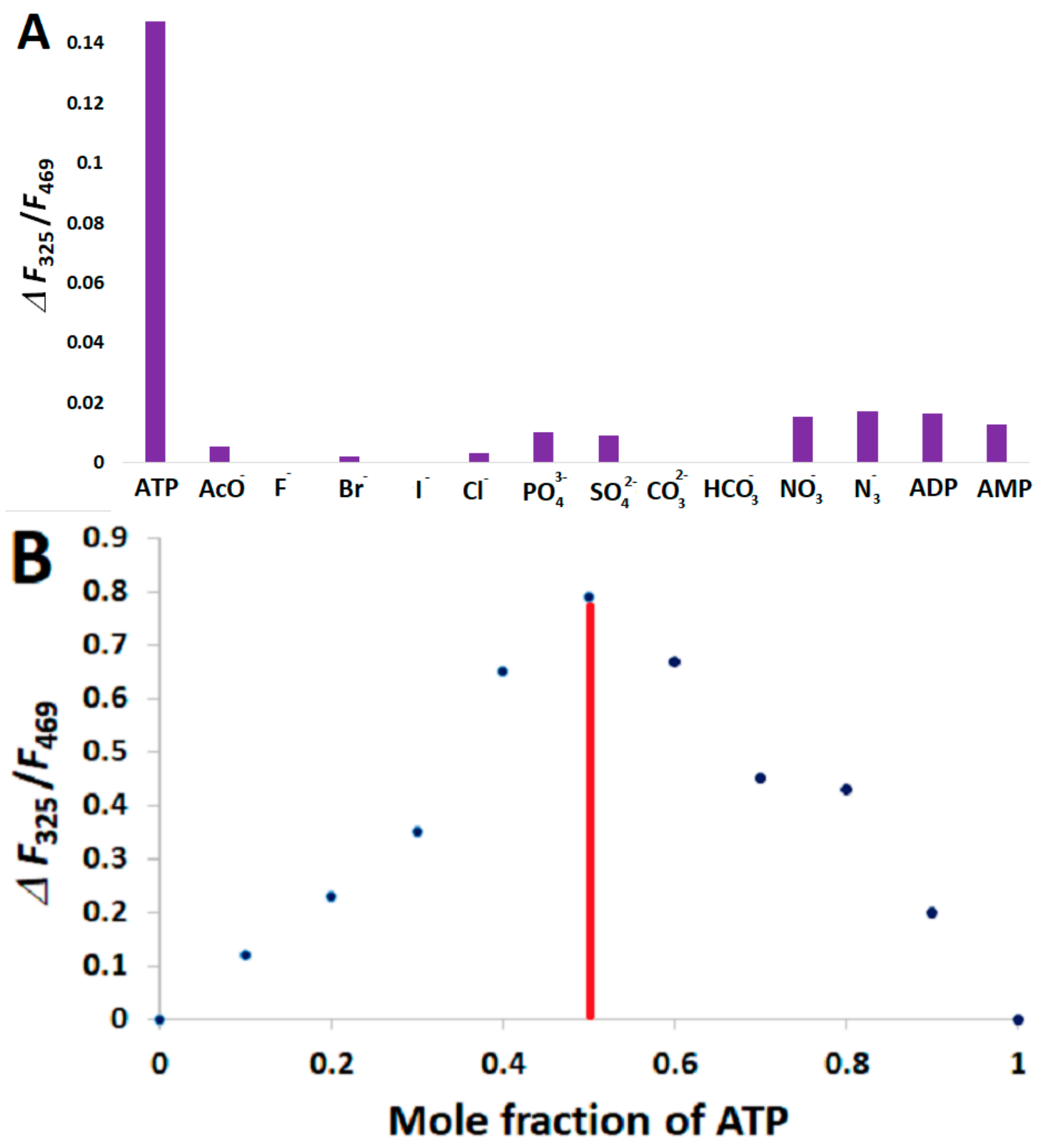

Figure 5. (A) The change in $F_{325} / F_{469}$ ratio of probe 5 in the presence of various anions in HEPES buffer (pH 7.5). (B) Job plot of 5 and ATP binding indicating 1:1 (5:ATP) binding stoichiometry. The relative concentrations of 5 and ATP were varied while the total concentration [5+ ATP] remained constant $(10 \mu \mathrm{M})$.

\subsection{Monitoring ATP Hydrolysis Reaction}

Apyrase (ATPase) is a magnesium-dependent enzyme that catalyzes the hydrolysis of ATP into AMP and inorganic phosphate [31]. Optimization of human apyrase has been proposed as a potential therapeutic strategy for arterial thrombosis based on its cardioprotective effect, rapid onset, and potent antiplatelet effect [32]. The sensitivity and selectivity of 5 towards ATP represents a promising platform to develop tools for monitoring apyrase activity. In the presence of $200 \mathrm{mU} / \mathrm{mL}$ of apyrase and ATP $(20 \mu \mathrm{M})$, the probe $5(10 \mu \mathrm{M})$ displays gradual enhancement in $\mathrm{F}_{469} / \mathrm{F}_{325}$ ratio until it reaches a plateau at $\sim 10 \mathrm{~min}$. Such response is attributed to the differential response of the probe 5 to ATP and its 
hydrolysis product AMP as previously demonstrated in Figure 4A. As shown in Figure 6, the variation in $\mathrm{F}_{469} / \mathrm{F}_{325}$ of 5 is dependent on the concentration of apyrase (ATPase) with smaller $\mathrm{F}_{469} / \mathrm{F}_{325}$ ratios at lower apyrase concentrations. Thus, these preliminary studies illustrate the potential utility of 5 in real-time monitoring of apyrase (ATPase) activity.

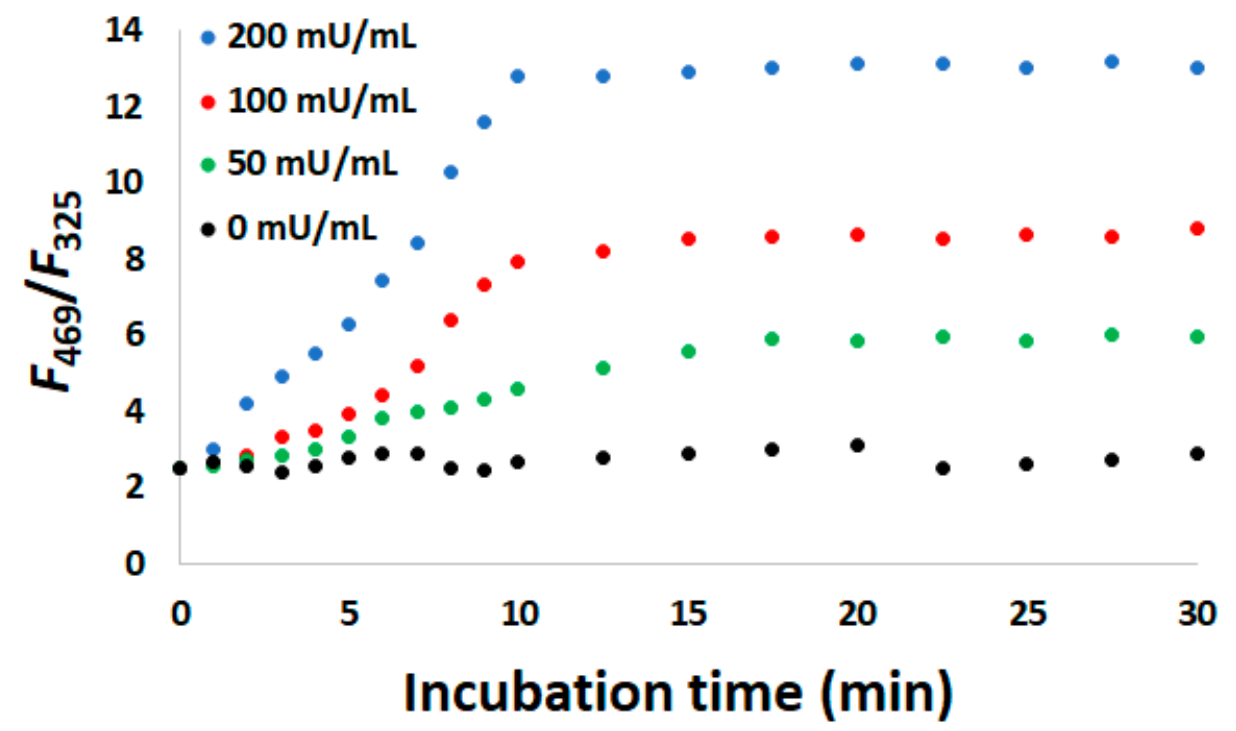

Figure 6. The variation in $\mathrm{F}_{469} / \mathrm{F}_{325}$ ratio of probe 5 as a function of apyrase (ATPase) concentration and incubation time. [5] $=10 \mu \mathrm{M},[\mathrm{ATP}]=20 \mu \mathrm{M}$.

\subsection{Computational Studies}

The stable conformers of probe 5 and ATP were optimized further at DFT level using Gaussian 16 quantum chemical program. The optimized structure of 5 and ATP are displayed in Figure 7A,B, respectively. Analysis of the stable structure of 5:ATP complex revealed that the negatively charged oxygens of two phosphate groups in ATP exhibit electrostatic interactions with positively charged ammonium center in probe 5 with distances less than $4 \mathrm{~A}^{\circ}$ as shown in Figure $7 \mathrm{C}$.

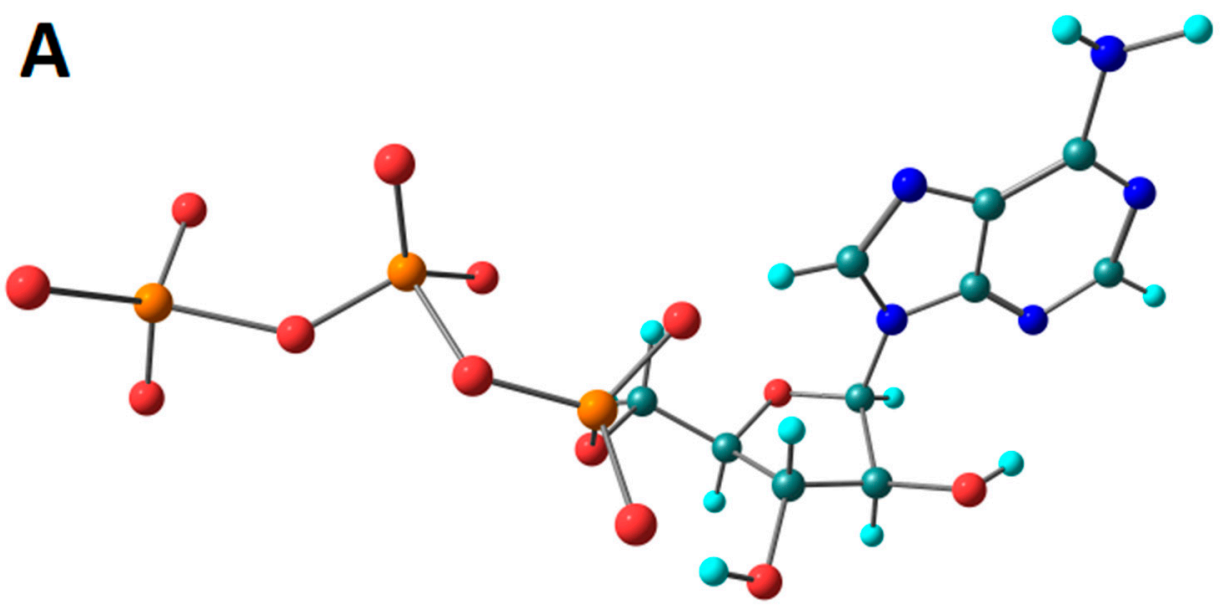

Figure 7. Cont. 

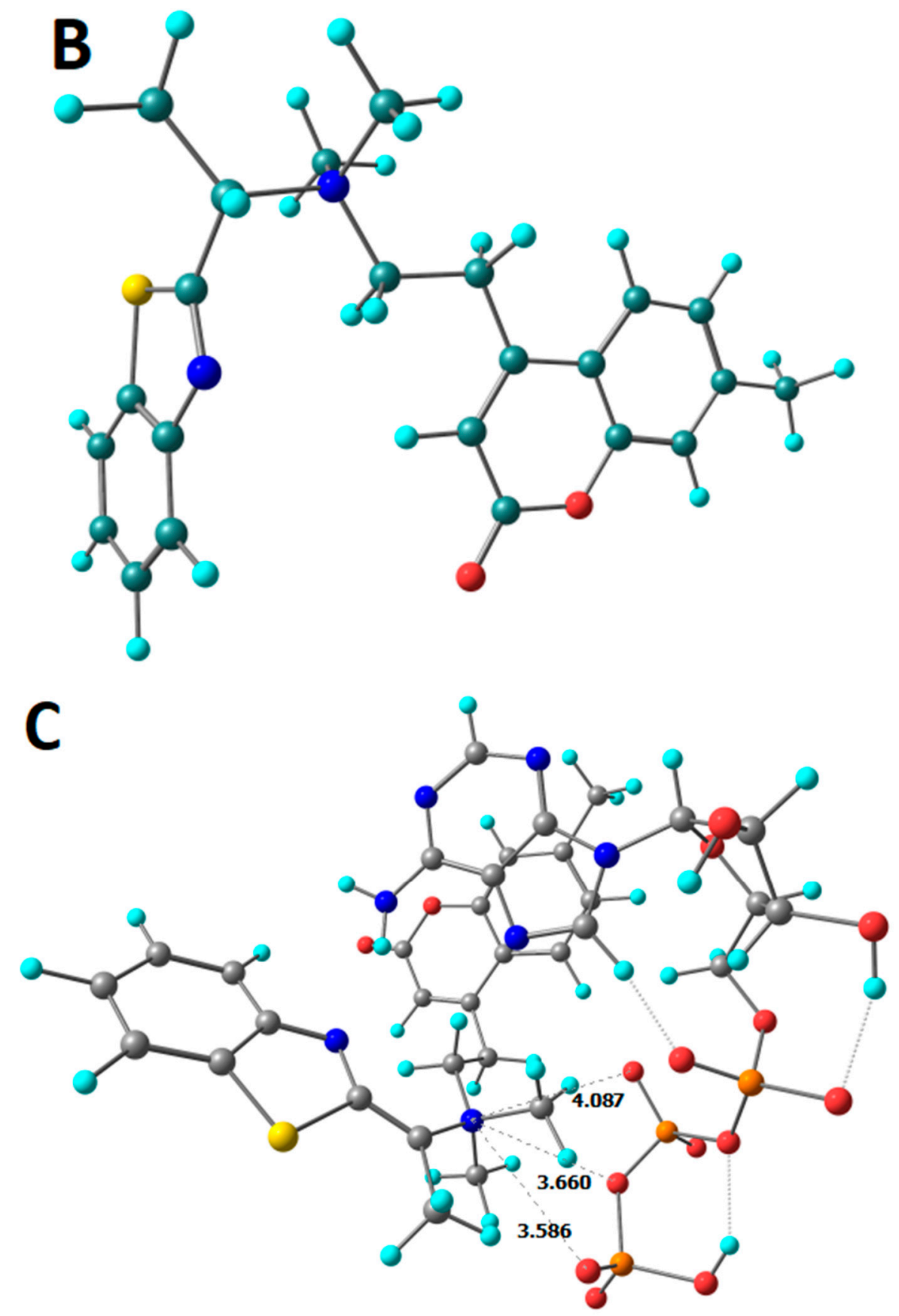

Figure 7. (A) Optimized geometry of ATP. (B) Optimized geometry of probe 5. (C) A model for potential electrostatic interaction between 5 and ATP.

\section{Conclusions}

In this study, a novel FRET sensor is introduced based on hybridization of coumarin and benzothiazole. The sensor exhibited remarkable sensitivity and selectivity to ATP in comparison to other NPP anions as well as a pool of 11 anions. Job plot analysis, Dynamic light scattering (DLS), and computational studies were employed to investigate the potential binding interaction between the probe 5 and ATP in aqueous solution. Interestingly, the probe revealed promising potential for real-time monitoring of ATP hydrolysis reactions which holds promise for future design and development of biological assays based on the reported FRET sensor 5 . 
Supplementary Materials: Supplementary material is available online at http://www.mdpi.com/2227-9040/7/3/34/ s1.

Author Contributions: M.T.G. and M.M.H.I.; methodology, M.T.G, A.T.; C.P.; writing一original draft preparation, M.T.G, M.M.H.I., A.T., C.P.; writing-review and editing, M.T.G.

Funding: This research received no external funding.

Conflicts of Interest: The authors declare no conflict of interest.

\section{References}

1. Chen, P.C. The contrast formation in optical microscopy. In Handbook of Biological Confocal Microscopy, 3rd ed.; Springer: Boston, MA, USA, 2006; pp. 162-206. [CrossRef]

2. Jares-Erijman, E.A.; Jovin, T.M. FRET imaging. Nat. Biotechnol. 2003, 21, 1387-1395. [CrossRef] [PubMed]

3. Shrestha, D.; Jenei, A.; Nagy, P.; Vereb, G.; Szollosi, J. Understanding FRET as a research tool for cellular studies. Int. J. Mol. Sci. 2015, 16, 6718-6756. [CrossRef] [PubMed]

4. Ding, Z.; Tan, J.; Feng, G.; Yuan, Z.; Wu, C.; Zhang, X. Nanoscale metal-organic frameworks coated with poly(vinyl alcohol) for ratiometric peroxynitrite sensing through FRET. Chem. Sci. 2017, 8, 5101-5106. [CrossRef] [PubMed]

5. Chen, Z.; Ding, Z.; Zhang, G.; Tian, L.; Zhang, X. Construction of thermo-responsive elastin-like polypeptides (ELPs)-Aggregation-Induced-Emission (AIE) conjugates for temperature sensing. Molecules 2018, 23, 1725. [CrossRef] [PubMed]

6. Ding, Z.; Wang, C.; Feng, G.; Zhang, X. Thermo-responsive fluorescent polymers with diverse LCSTs for ratiometric temperature sensing through FRET. Polymers 2018, 10, 283. [CrossRef]

7. Kikuchi, K.; Takakusa, H.; Nagano, T. Recent advances in the design of small molecule-based FRET sensors for cell biology. Trends Anal. Chem. 2004, 23, 407-415. [CrossRef]

8. Lundin, A.; Thore, A. Comparison of methods for extraction of bacterial adenine nucleotides determined by firefly assay. Appl. Microbiol. 1975, 30, 713-721. Available online: https://www.ncbi.nlm.nih.gov/pmc/ articles/PMC187260/ (accessed on 6 July 2019).

9. Traut, T.W. Physiological concentrations of purines and pyrimidines. Mol. Cell Biochem. 1994, 140, 1-22. [CrossRef]

10. Tsuyama, T.; Kishikawa, J.; Han, Y.-W.; Harada, Y.; Tsubouchi, A.; Noji, H.; Kakizuka, A.; Yokoyma, K.; Uemura, T.; Imamura, H. In vivo fluorescent adenosine $5^{\prime}$-triphosphate (ATP) imaging of Drosophila melanogaster and Caenorhabditis elegans by using a genetically encoded fluorescent ATP biosensor optimized for low temperatures. Anal. Chem. 2013, 85, 7889-7896. [CrossRef]

11. Conley, J.M.; Radhakrishnan, S.; Valentino, S.A.; Tantama, M. Imaging extracellular ATP with a genetically-encoded ratiometric fluorescent sensor. PLoS ONE 2017, 12, e0187481. [CrossRef]

12. Nakano, S.; Shimizu, M.; Dinh, H.; Morii, T. Highly selective dual sensing of ATP and ADP using fluorescent ribonucleopeptide sensors. Chem. Commun. 2019, 55, 1611-1614. [CrossRef] [PubMed]

13. Wu, Y.; Wen, J.; Li, H.; Sun, S.; Xu, Y. Fluorescent probes of ATP. Chin. Chem. Lett. 2017, 28, $1916-1924$. [CrossRef]

14. Tan, K.Y.; Li, C.Y.; Li, Y.F.; Fei, J.; Yang, B.; Fu, Y.J.; Li, F. Real-time monitoring ATP in mitochondrion of living cells: A specific fluorescent probe for ATP by dual recognition sites. Anal. Chem. 2017, 89, 1749-1756. [CrossRef] [PubMed]

15. Jun, Y.W.; Sarkar, S.; Kim, K.H.; Ahn, K.H. Molecular probes for fluorescence imaging of ATP in cells and tissues. ChemPhotoChem 2019, 3, 214-219. [CrossRef]

16. Rao, A.S.; Kim, D.; Nam, H.; Jo, H.; Kim, K.H.; Ban, C.; Ahn, K.H. A turn-on two-photon fluorescent probe for ATP and ADP. Chem. Commun. 2012, 48, 3206-3208. [CrossRef]

17. Zhou, Y.; Xu, Z.; Yoon, J. Fluorescent and colorimetric chemosensors for detection of nucleotides, FAD and NADH: Highlighted research during 2004-2010. Chem. Soc. Rev. 2011, 40, 2222-2235. [CrossRef]

18. Xue, L.; Liu, C.; Jiang, H. A ratiometric fluorescent sensor with a large Stokes shift for imaging zinc ions in living cells. Chem. Commun. 2009, 1061-1063. [CrossRef]

19. Tang, J.-L.; Li, C.-Y.; Li, Y.-F.; Zou, C.-X. A ratiometric fluorescent probe with unexpected high selectivity for ATP and its application in cell imaging. Chem. Commun. 2014, 50, 15411-15414. [CrossRef] 
20. Bojtar, M.; Janzso-Berend, P.Z.; Mester, D.; Hessz, D.; Kallay, M.; Kubinyi, M.; Bitter, I. An uracil-linked hydroxyflavone probe for the recognition of ATP. Beilstein J. Org. Chem. 2018, 14, 747-755. [CrossRef]

21. Kurishita, Y.; Kohira, T.; Ojida, A.; Hamachi, I. Rational design of FRET-based ratiometric chemosensors for in vitro and in cell fluorescence analyses of nucleoside polyphosphates. J. Am. Chem. Soc. 2010, 132, 13290-13299. [CrossRef]

22. Zeng, Z.; Torriero, A.A.J.; Bond, A.M.; Spiccia, L. Fluorescent and electrochemical sensing of polyphosphate nucleotides by ferrocene functionalised with two $\mathrm{Zn}^{\mathrm{II}}(\mathrm{TACN})$ (pyrene)complexes. Chem. Eur. J. 2010, 16, 9154-9163. [CrossRef] [PubMed]

23. Widmer, S.; Dorrestijn, M.; Camerlo, A.; Urek, S.K.; Lobnik, A.; Housecroft, C.E.; Constable, E.C.; Scherer, L.J. Coumarin meets fluorescein: A Forster resonance energy transfer enhanced optical ammonia gas sensor. Analyst 2014, 139, 4335-4342. [CrossRef] [PubMed]

24. Wang, M.; Wen, J.; Qin, Z.; Wang, H. A new coumarin-rhodamine FRET system as an efficient ratiometric fluorescent probe for $\mathrm{Hg}^{2+}$ in aqueous solution and living cells. Dyes Pigment. 2015, 120, 208-212. [CrossRef]

25. Kim, J.H.; Sumranjit, J.; Kang, H.J.; Chung, S.J. Discovery of coumarin derivatives as fluorescence acceptors for intrinsic fluorescence resonance energy transfer of proteins. Mol. Biosyst. 2014, 10, 30-33. [CrossRef] [PubMed]

26. Yang, L.; Wang, C.; Chang, G.; Ren, X. Facile synthesis of new coumarin-based colorimetric and fluorescence chemosensors: Highly efficient and selective detection of $\mathrm{Pd}^{2+}$ in aqueous solutions. Sens. Actuators Chem. B 2017, 240, 212-219. [CrossRef]

27. Chang, C.; Wang, F.; Wei, T.; Chen, X. Benzothiazole-based fluorescent sensor for ratiometric detection of $\mathrm{Zn}(\mathrm{II})$ ions and secondary sensing PPi and its applications for biological imaging and PPase catalysis assays. Ind. Eng. Chem. Res. 2017, 56, 8797-8805. [CrossRef]

28. Erdemir, S.; Tabakci, B. Selective and sensitive fluorescein-benzothiazole based fluorescent sensor for $\mathrm{Zn}^{2+}$ ion in aqueous media. J. Fluoresc. 2017, 27, 2145-2152. [CrossRef]

29. Erdemir, S.; Malkondu, S.; Alici, O. A highly selective and sensitive benzothiazole-based 'turn-on' fluorescent sensor for $\mathrm{Hg}^{2+}$ ion. Color. Technol. 2015, 131, 32-37. [CrossRef]

30. Wang, H.; Zhang, H.; Chen, Y.; Huang, K.; Liu, Y. A label-free and ultrasensitive fluorescent sensor for dopamine detection based on double-stranded DNA templated copper nanoparticles. Sens. Actuators B 2015, 220, 146-153. [CrossRef]

31. Pilla, C.; Emanuelli, T.; Frassetto, S.S.; Battastini, A.M.; Dias, R.D.; Sarkis, J.J. ATP diphosphohydrolase activity (apyrase, EC 3.6.1.5) in human blood platelets. Platelets 1996, 7, 225-230. [CrossRef]

32. Moeckel, D.; Jeong, S.S.; Sun, X.; Broekman, M.J.; Nguyen, A.; Drosopoulos, J.H.F.; Marcus, A.J.; Robson, S.C.; Chen, R.; Abendschein, D. Optimizing human apyrase to treat arterial thrombosis and limit reperfusion injury without increasing bleeding risk. Sci. Transl. Med. 2014, 6, 248ra105. [CrossRef] [PubMed] 